\title{
533454
}

\section{C-COUPON STUDIES OF CMCS: FRACTURE BEHAVIOR AND MICROSTRUCTURAL CHARACTERIZATION}

\author{
Frances I. Hurwitz, Anthony M. Calomino \\ NASA Glenn Research Center \\ Cleveland, $\mathrm{OH} 44135$
}

Terry R. McCue

Dynacs Engineering Co., Inc.

Brookpark, OH 44142

\author{
Ali Abdul-Aziz \\ Cleveland State University \\ Cleveland, $\mathrm{OH} 44115$
}

\begin{abstract}
A curved beam "C-coupon" was used to assess fracture behavior in a Sylramic ${ }^{\text {TM/melt }}$ infiltration (MI) SiC matrix composite. Failure stresses and fracture mechanisms, as determined by optical and scanning electron microstructual analysis, are compared with finite element stress calculations to analyze failure modes. Material microstructure was found to have a strong influence on mechanical behavior. Fracture occurs in interlaminar tension (ILT), provided that the ratio of ILT to tensile strength for the material is less than the ratio of radial to hoop stresses for the C-coupon geometry. Utilization of 3D architectures to improve interlaminar strength requires significant development efforts to incorporate through thickness fibers in regions with high curvatures while maintaining uniform thickness, radius and microstructure.
\end{abstract}

\section{INTRODUCTION}

The use of ceramic matrix composites (CMCs) in aerospace parts having high curvatures, or thickness transitions, introduces interlaminar stresses which can approach or exceed the interlaminar strength of a material. The ability to measure transverse tensile properties at elevated temperature is therefore critical. The "C-coupon" geometry ${ }^{1 / 4}$ provides a configuration suitable for evaluating interlaminar tension strength, with an additional advantage of assessing the fabrication effects of sharply curved regions with and without three dimensional (3D) fiber reinforcement architectures. ${ }^{5,6}$

In this work, fracture tests were conducted under tensile loading of $\mathrm{C}$-coupons fabricated using Sylramic ${ }^{T M}$ fiber / MI materials. Test results are discussed in relation to the material microstucture and supporting stress analysis of the of the specimen's geometry using elastic properties for the CMC measured from 8 ply, $5 \mathrm{HS} 0 / 90 \mathrm{CMC}$ flat panels. Both the microstructure and fracture damage were characterized for a variety of specimens, representing several 3D architectures in addition to three lots of materials with the standard 8-ply layup of 0/90 5HS material (referred to as baseline material). publication. Because of changes that may be made before formal publication, this preprint is made available with the understanding that it will not be cited or reproduced without the permission of the author. 
Specimens were manufactured and tested under the Enabling Propulsion Materials (EPM) Program ${ }^{1,8}$, a joint effort in which Pratt and Whitney, GE Aircraft Engines and NASA were teamed.

\section{EXPERIMENTAL}

Specimens were fabricated by Honeywell Composites (Newark, DE) using preforms of Sylramic ${ }^{\mathrm{TM}}$ fiber cloth having a chemical vapor infiltration (CVI) BN interphase, and a CVI SiC overcoat. Preforms were then SiC slurry cast and infiltrated with a silicon melt to achieve final density. Specimens of $25.4 \mathrm{~mm}$ width were sectioned from "logs" of material having an inner radius of $7.62 \mathrm{~mm}$. Fast fracture ensile testing at room temperature and $1093^{\circ} \mathrm{C}$ in air was conducted by Southern Research Institute (Birmingham, $\mathrm{AL}$ ). The distance from the load point to the center of curvature was 31.8 $\mathrm{mm}$ and the loading rate was $44.5 \mathrm{~N} / \mathrm{min}$. A fixtured C-coupon is shown in Figure 1.

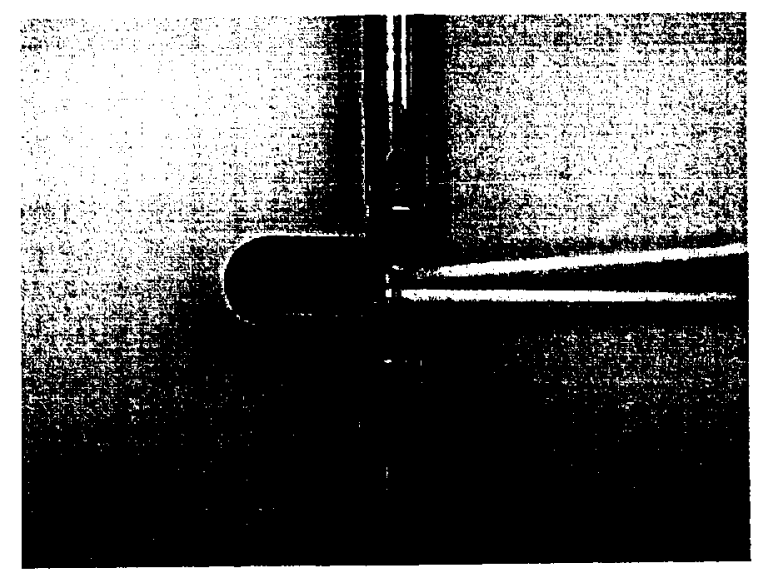

Figure 1. "C-specimen" shown mounted in test fixture with extensometer.

Two and three-dimensional finite element analyses were completed for the combined force and moment loading conditions. The structural response was evaluated by identifying regions of peak radial and hoop stress. The analyses used elastic properties of flat panels manufactured by Honeywell in September 1999 (herein referred to as the $9 / 99$ material) to establish baseline properties for this $\mathrm{CMC} .{ }^{9}$ Details of the analysis are presented in a companion paper published elsewhere in this volume.

Material microstructure and post-failure damage evaluations were assessed by optical microscopy of specimens that were vacuum infiltrated with epoxy and polished, and by field emission electron microscopy (FESEM) and energy dispersive spectroscopy (EDS) of fracture surfaces. Three different lots of baseline material were examined together with the T-pinned, angle interlock and orthogonal weave 3D architectures. All fiber architectures were manufactured by Albany International Techniweave (Rochester, NH). 


\section{RESULTS AND DISCUSSION}

It is important to note that the Sylramic ${ }^{\mathrm{TM}} / \mathrm{MI}$ CMC material evolves with time and fabrication experience so any assessment of its mechanical behavior must be viewed in light of the fabrication date and material microstructure. This is demonstrated in examination of the various baseline lots of material which have shown continuous improvement in microstructural uniformity and mechanical performance with time. The most recently manufactured lot (0253-01-007) of 8 ply 5 HS material characterized in this study exhibited the highest load bearing capability of the three lots examined. The typical microstructure for this lot of material is shown in Figure 2. In room temperature and elevated temperature tests, this material exhibited delamination failures, as well as fracture initiating on the inner surface of the radius within $+1-45^{\circ}$ of the centerline, as

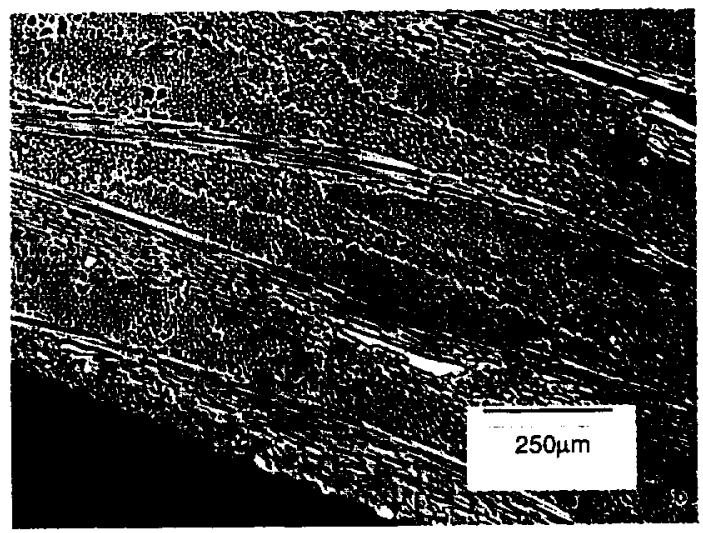

Figure 2. Microstructure of 5 HS specimen, lot 0253-01-007 showing good infiltration and well spread tows.

shown in Figure 3. Delamination fractures propagated in the hoop direction. These occurred between multiple ply layers in several specimens, and may represent successive fracture as loading continues. Cracks initiating on the tensile surface propagated radially and often branched. Because these samples were tested in load control, and continued to be loaded after failure, fractures due to hoop stresses are expected to have occurred subsequent to ILT fracture.

The observed damage is consistent with the finite element analysis, which shows the maximum hoop stress at the tensile surface, and maximum radial stress midway through the thickness, tapering off at $40^{\circ}$ to $45^{\circ}$ on either side of the specimen centerline. Older batches of the baseline material having poorer microstructure (i.e., tighter tows and many more voids), failed at significantly lower stress levels, and exhibited delamination failures only.

The interlaminar tensile (ILT) strength of the $9 / 99$ baseline material, as measured on flat panels, exhibited a mean of $15.5 \mathrm{MPa}$ ( 24 samples from 3 lots of material), while the in-plane tensile strength was $420 \mathrm{MPa}$, a ratio of 0.036 . The analysis of the $\mathrm{C}$ coupon 


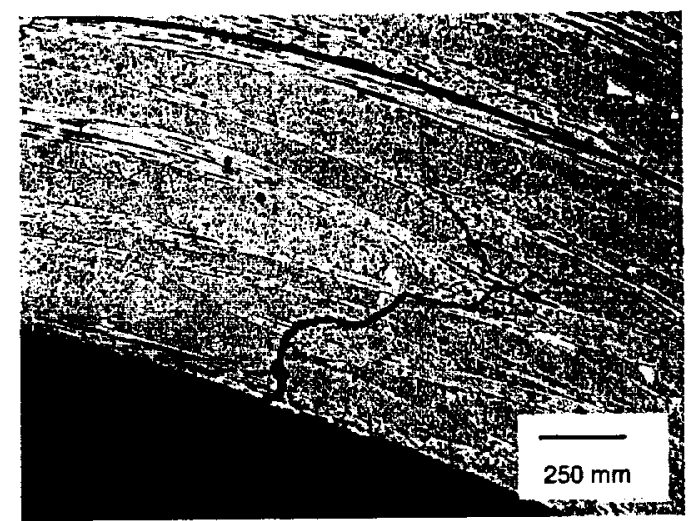

Figure 3. Typical fracture observed in 5 HS specimen, room temperature test.

predicts a ratio of maximum radial stress to maximum hoop stress of 0.064 . Therefore, radial stresses should exceed the expected ILT strength well before the hoop stress reaches its expected strength of $420 \mathrm{MPa}$, with delamination occurring well before Mode I cracking. (The effects of delamination on load redistribution have not been analyzed.) In an older batch of material (9/98), ILT strengths were comparable (14.8 $\mathrm{MPa})$ to the $9 / 99$ composites, but tensile strengths were considerably lower (220MPa), producing a stress ratio of 0.068 , and rendering mixed mode fracture likely.

Representative load-displacement curves for the 8 ply 5 HS Lot 0253-001-007 EPM Cspecimens are shown in Figure 4. Testing was conducted in load control, so that no load drop which can be attributed to initial cracking is seen. Based on finite element analysis

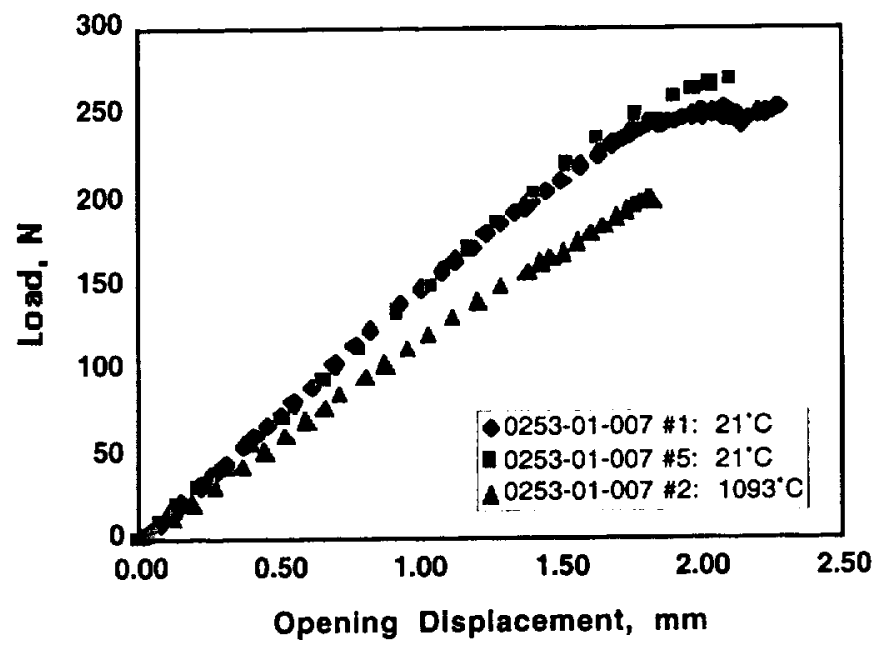

Figure 4: Load-displacement curves for 8 ply, 5 HS composite at ambient and elevated temperatures. 
of radial stress as a function of $h / r_{m}$, room temperature fracture occurred at a radial stress of $29-30 \mathrm{MPa}$ and a maximum hoop stress of $420-450$, close to the ultimate tensile strength of the $9 / 99$ material. Therefore, for these samples, mixed mode fracture cannot be ruled out.

Fracture surfaces from room temperature tests exhibited "saw tooth" patterns characteristic of shear failure, as shown in Figure 5. The majority of the delaminations occurred between the BN interphase and the SiC overcoat, as shown in Figures 6 and 7, although occasional bare fibers also were seen (Figure 7). The BN interface possessed a

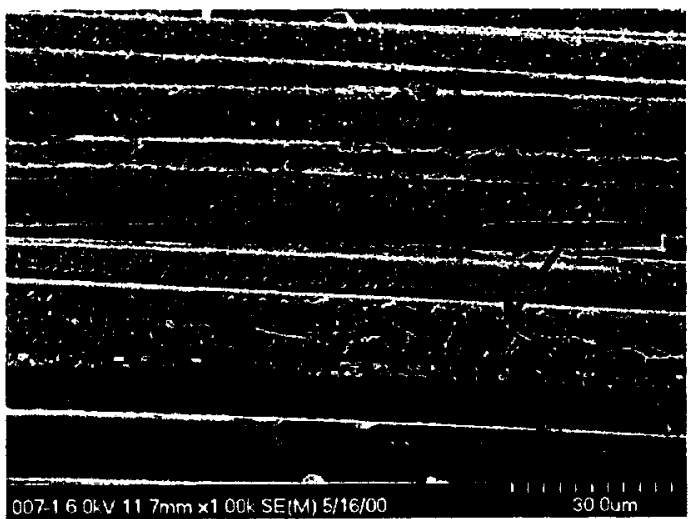

Figure 5 Fracture surface of 5 HS coupon showing indication of shear. Failure appears to have occurred between the $\mathrm{BN}$ and $\mathrm{CVI}$ $\mathrm{SiC}$ layers.

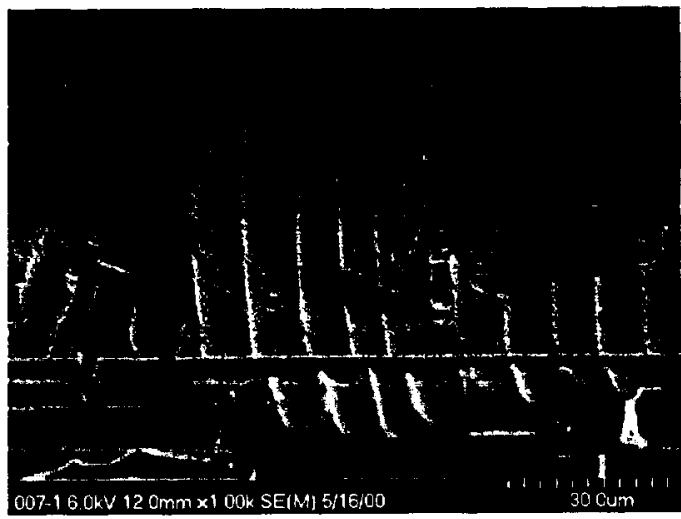

Figure 6. SiC "troughs" in 8 ply 5 HS sample fractured at room temperature.

"bumpy" appearance (Figure 7), which, though not typical of the Sylramic ${ }^{\mathrm{TM}} / \mathrm{MI}$ CMC, has occasionally been observed in other lots of material outside of the present work. The "smooth" BN coating shown in Figure 8 is more typical of the majority of material lots, and had a higher percentage of fracture between the fiber surface and the BN. The "bumpy" BN coating was found by EDS at $6 \mathrm{kV}$ to contain $\mathrm{Cl}$ (Figure 7), not observed in the smooth BN (Figure 8), and relatively less $\mathrm{C}$. (The Ti arises from the Sylramic ${ }^{\mathrm{TM}}$ fiber.) Whether the $\mathrm{Cl}$ and $\mathrm{C}$ incorporation alone explains the difference in $\mathrm{BN}$ morphology is not understood at this point, but adds to the evidence of lot to lot material variations.

Since a limited number of specimens were tested, and only those which failed in two pieces could be examined by SEM, a fracture surface from an elevated temperature test was not available for comparison at this time.

Due to the low ILT strength of the baseline material, it is thought that $3 \mathrm{D}$ architectures with through thickness fibers will improve interlaminar properties. C-coupons having 3D architectures that included angle interlocks and T-pinning were fabricated and tested. Weaving using a conventional orthogonal architecture with Sylramic ${ }^{\mathrm{TM}}$ fiber resulted in 

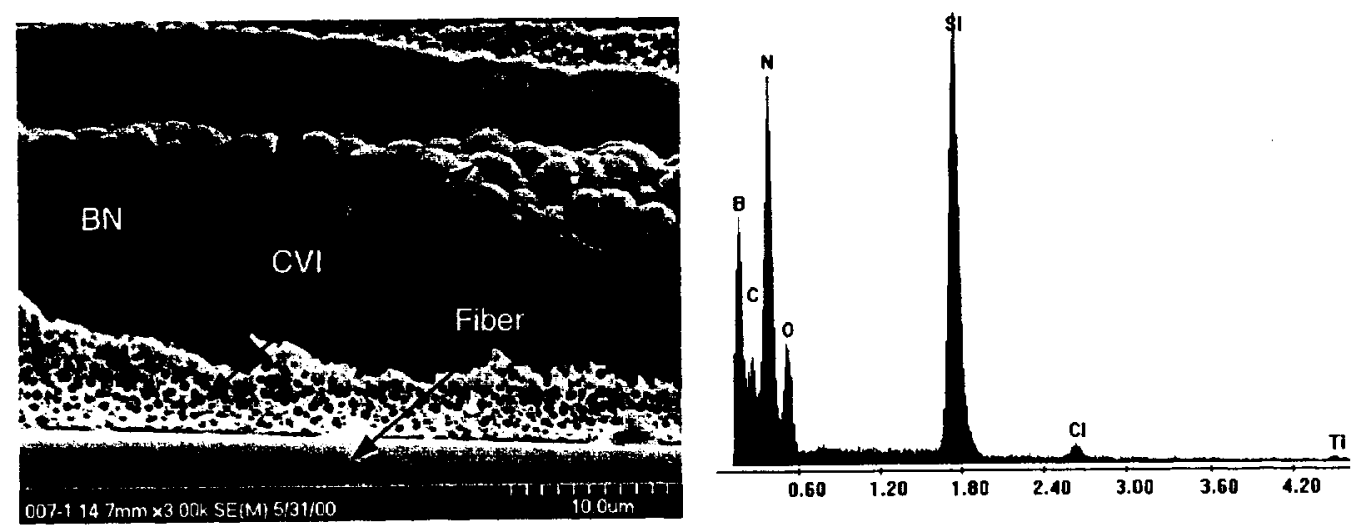

Figure 7. Fracture surface, 5HS specimen with "bumpy" BN interphase coating. EDS spectra of $\mathrm{BN}$ coating at $6 \mathrm{kV}$ is at right.
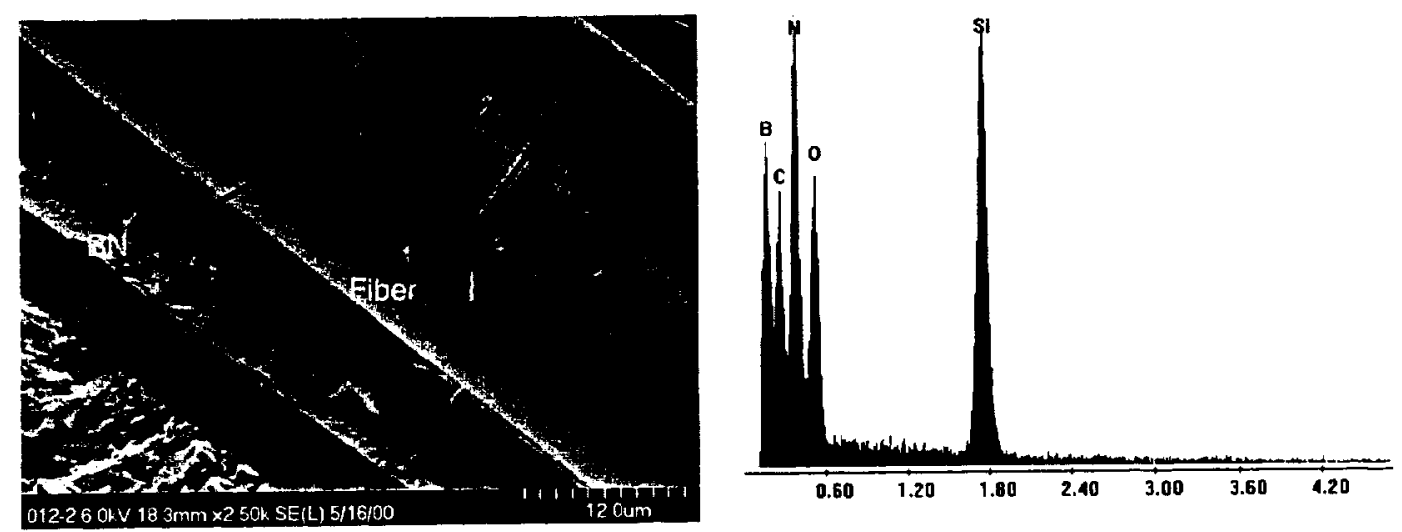

Figure 8. Elevated temperature fracture of specimen with smooth BN interphase coating. EDS spectra of coating at $6 \mathrm{kV}$ is at right.

broken fibers due to high stiffness, (nominally estimated as $400 \mathrm{GPa}$ ), necessitating modifying the weave so that the $\mathrm{Z}$ fiber crossed two tows rather than the usual one in turning. The resulting weaves also proved to present challenges for matrix infiltration and specimen consolidation. The orthogonal (Figure 9) and angle interlock specimens had rather low fiber volume fractions, as well as non-uniform fiber spacing, resulting in matrix rich regions and numerous voids. Fiber misalignment also occurred because weaving was performed on flat material which was then formed to the curved C. Maximum loads at failure were 113-129 N for the angle interlock, and 64-125 N for the orthogonal weave, as compared with $200-268 \mathrm{~N}$ for the baseline 8 ply 5 HS layup.. The fracture patterns for these specimens displayed the same mixed mode failure patterns observed in the baseline material. 
The T-pinned architecture proved to be the most difficult material to fabricate. Because the $\mathrm{T}$-pin fibers prevented ply compression, resulting $\mathrm{C}$-coupons were thicker than the baseline counterpart and did not fit well into the tooling. This led to large variation in the thickness and non-uniformity of the radius in the bend regions, large matrix rich regions, and much thicker samples. Despite the poor microstructures obtained, the maximum stresses at failure equaled those of the baseline specimens. The failure mode was strictly tensile fracture in the radial direction (Figure 10). Cracks running parallel to the hoop direction were seen only in the matrix rich region on the outer surface of the composite radius, which is in compression, demonstrating that through thickness reinforcement can improve the interlaminar strength of the composite.

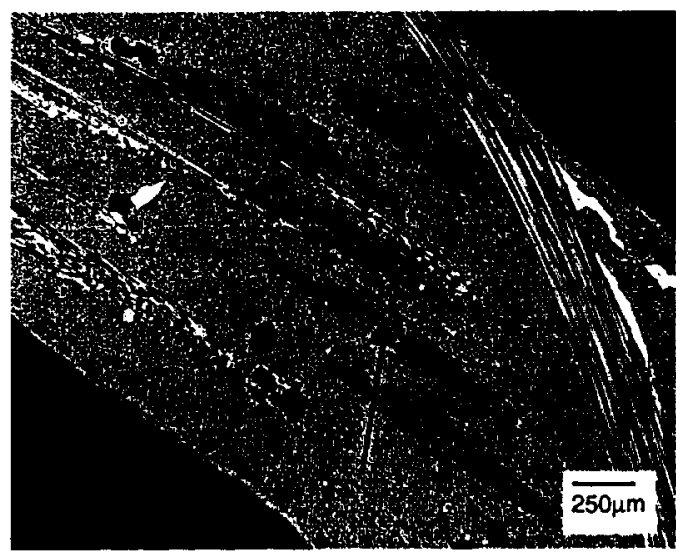

Figure 9. Orthogonal weave tested at room temperature. Arrow indicates fracture.

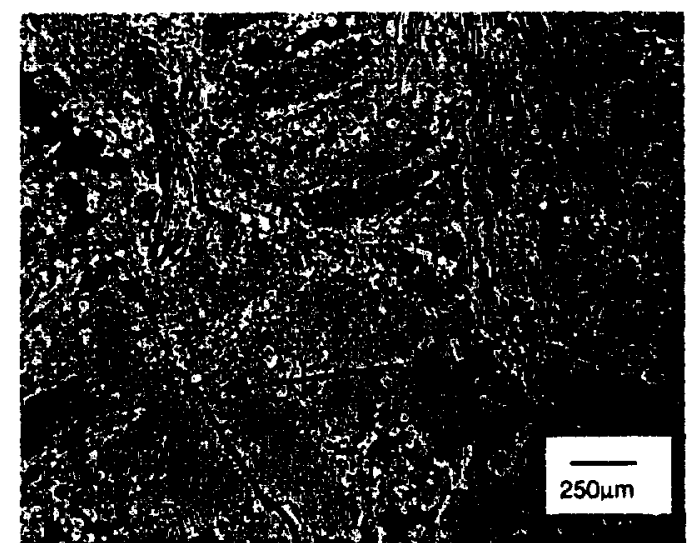

Figure 10 T-pinned specimen fractured at room temperature, showing radial fracture.

However, there is a further need for development of weaving techniques for the T-pinned architecture to be used. The through thickness yarns used here were served with a carbon fiber, and large areas of carbon remained in the sample, which would be undesirable under oxidizing conditions.

\section{SUMMARY AND CONCLUSIONS}

The C-coupon affords a small, readily analyzable shape with variable bend radius useful for optimizing fabrication of CMCs containing bends, as well as improving resistance to delamination stresses by studying the effect of fiber architecture. It is able to be used to measure ILT strengths of materials at both room and elevated temperatures provided that the ratio of ILT to tensile strengths of the material is significantly less than the ratio of 0.064 for the geometry used here. For materials in which this is not the case, specimen geometry will need to be altered so that an appropriate ratio for assuring interlaminar fracture is achieved. 
The samples tested here represented materials fairly low on the learning curve in forming shapes with small radii. The $5 \mathrm{HS}$ material lots represent an evolution in processing of the Sylramic ${ }^{\mathrm{TM}} / \mathrm{MI}$ CMCs even for flat panels. Much development work is needed to introduce 3D reinforcement in bend regions of parts. Avoidance of cracks parallel to the hoop direction entirely in the T-pinned material serve as proof of concept that $3 \mathrm{D}$ reinforcement can improve properties if fabrication techniques can be advanced to achieve more uniform bend radii with this architecture.

It is interesting to note that fracture occurred between the $\mathrm{BN}$ and CVI SiC layers, at least for samples with "bumpy" BN morphology; this might serve as an area of focus for improving interlaminar properties.

\section{ACKNOWLEDGMENTS}

The authors wish to thank Ron Cairo, formerly of Pratt and Whitney, and Terry Barnett of Southern Research Institute for helpful discussions.

\section{REFERENCES}

${ }^{1}$ L. A. Carlsson, F. Ozdil, "Interlaminar Fracture of CMCs and Button Specimen Benchmark Testing, Task A6, High Speed Research/ Enabling Propulsion Materials Program, Final Technical Report" (NASA, Pratt and Whitney, GE Aircraft Engines, October 31, 1999).

${ }^{2}$ G. Y. Cui, C. Ruiz, Through-Thickness Failure of Laminated C/Epoxy Composites under Combined Stress, SEM Spring Conf. Exp. Mechanics (Society for Experimental Mechanics, Bethel, CT, 1994).

${ }^{3}$ W. L. Ko, R. H. Jackson, Multilayer Theory for Delamination Analysis of a Composite Curved Bar Subjected to End Forces and End Moments, 5th International Conference on Composite Structures, Paisley, Scotland (1989).

${ }^{4}$ T. J. Lu, Z. C. Xia, J. W. Hutchinson, "Delamination of Beams under Transverse Shear and Bending," Mater. Sci. Eng., A 188, 103-12(1194).

${ }^{5}$ M. He, B. N. Cox, "Crack Bridging by Through-Thickness Reinforcement in Delaminating Curved Structures," Composites, A 29, 377-393 (1998).

${ }^{6}$ T.-J. Lu, J. W. Hutchinson, "Role of Fiber Stitching in Eliminating Transverse Fracture in Cross-Ply Ceramic Composites," J. Am. Ceram. Soc. 78, 251-53 (1995).

7 A. Abdul-Aziz, F. I. Hurwitz, D. N. Brewer, A. M. Calomino, "C-Coupon Studies of CMCs: Fracture Behavior and Microstructural Characterization," Ceram. Eng. and Sci. Proc., this volume, (2001).

${ }^{8}$ R. R. Cairo, "Fiber Architecture Study, High Speed Research/Enabling Propulsion Materials Program, internal communication." (NASA, Pratt and Whitney, GE Aircraft Engines, October, 1999).

${ }^{\circ}$ A. M. Calomino, Personal communication, June, 2000. 